\title{
Promethazine-Tetraphenyl Boron(III) Modified Carbon Paste Electrode for the Determination of Promethazine Hydrochloride
}

\author{
Sayed Sayed Badawy", Sherif Abo El Seoud El Said \\ Department of Chemistry, Faculty of Science, Cairo University, Cairo, Egypt \\ Email: "ssbadawy@yahoo.com
}

Received February 21, 2013; revised March 25, 2013; accepted April 28, 2013

Copyright (C) 2013 Sayed Sayed Badawy, Sherif Abo El Seoud El Said. This is an open access article distributed under the Creative Commons Attribution License, which permits unrestricted use, distribution, and reproduction in any medium, provided the original work is properly cited.

\begin{abstract}
Promethazine modified carbon paste ion selective electrode has been prepared, based on the ion pair of promethazine hydrochloride $\mathrm{Pm} . \mathrm{Cl}$ with sodium tetraphenyl boron(III) Pm-TPB dissolved in dioctyl phthalate DOP as a pasting liquid. The electrode showed the linear response with mean calibration graph slope of $58 \mathrm{mV} /$ decade at $25^{\circ} \mathrm{C}$; at a concentration range and a lower detection limit of $1 \times 10^{-5}-6 \times 10^{-2} \mathrm{M}$ and $8 \times 10^{-6} \mathrm{M}$ promethazine hydrochloride, respectively. The change of $\mathrm{pH}$ of the tested solution within the range $4.2-6.8$ did not affect the electrode performance. The electrode showed a very good selectivity toward $\mathrm{Pm}+$ cations with respect to a large number of organic and inorganic cations and compounds. The standard addition and potentiometric titration methods were applied for the determination of promethazine hydrochloride in pure solution and in pharmaceutical preparations with an average recovery range of $97.3 \%-101.4 \%$ and a mean relative standard deviation (RSD) of $0.35 \%-1.83 \%$ which were of comparable accuracy and precision to the previously reported works.
\end{abstract}

Keywords: Carbon Paste Electrode; Ion Pair; Promethazine Hydrochloride; Phenergan (Syrup)

\section{Introduction}

Promethazine hydrochloride [N,N-dimethyl-1-(10H-phenothiazine-10-yl)propan-2-amine] hydrochloride, belonging to phenothiazine group (Scheme 1), is widely used as antihistaminic, sedative, antiemetic, antipsychotic, analgesic and anticholinergic drug.

Several methods have been reported for the quantitative determination of promethazine in pure solution and/ or in pharmaceutical preparations. These methods were mainly chromatographic which, in spite of their good sensitivities, are very expensive, time consuming and require special training. They include LC-MS [1], HPLC [2-7], GLC [8-10], turbidimetry [11], high performance capillary electrophoresis $[12,13]$, nephelometric and conductmetric titrations $[14,15]$, chemometric calibration [16], (square wave adsorptive [17]; anodic striping [18]; differential pulse adsorptive $[19,20]$; cyclic $[21,22]$ ) voltamertic methods of analysis, PVC membrane potentiometry $[23,24]$ and UV-visible spectrophotometry [25-31].

In the present work, a new chemically modified carbon

"Corresponding author. paste electrode for Promethazine cations was constructed and its performance characteristics were studied. The electrode was successfully used for the determination of Pm.Cl in pure solution and in pharmaceutical preparations.

\section{Experimental}

\subsection{Apparatus}

Potentiometric and $\mathrm{pH}$ measurements were carried out by using HANNA pH-mV meter model 8519, a Techne circulator thermostat Model C-100 to control the tempera-<smiles>CC(CN1c2ccccc2Sc2ccccc21)N(C)Cl</smiles>

Scheme 1. Promethazine hydrochloride. 
ture of the test solution and an $\mathrm{Ag} / \mathrm{AgCl} / 3 \mathrm{M} \mathrm{KCl}$ reference electrode model Metrohm 6.0733.100. The electrochemical system of the measurements may be represented as follows: CMCPE/test solution//reference electrode.

\subsection{Materials and Reagents}

All reagents were of analytical reagent grade. Doublydistilled water was used throughout all experiments. Promethazine hydrochloride was provided by Alexandria Pharmaceutical Industries Co., Alexandria, Egypt. The Pharmaceutical preparations [Phenergan syrup, Promethazine hydrochloride $1 \mathrm{mg} / \mathrm{ml}$ ] and [Phenergan syrup, Expectorant, (Promethazine hydrochloride $1 \mathrm{mg} / \mathrm{ml}$, thicol $45 \mathrm{mg} / \mathrm{ml}$ and Ipecacuanha extract $3 \mathrm{mg} / \mathrm{ml}$ )] were obtained from local drug stores. Graphite powder (Fluka). Sodium tetraphenyl borate NaTPB, dioctyl phthalate DOP, dibutyl phthalate DBP, o-nitrophenyl octyl ether ONPOE, diisononyl phthalate DINP and paraffin oil PO were obtained from Aldrich chemical company.

\subsection{Preparation of the Ion Exchanger}

The ion exchanger, Promethazine tetraphenyl borate PmTPB, was prepared by adding $50 \mathrm{ml} 0.01 \mathrm{M}$ of promethazine hydrochloride to $50 \mathrm{ml} 0.01 \mathrm{M}$ of NaTPB. The formed white precipitate was filtered off, washed thoroughly with doubly-distilled water, dried at room temperature and ground to fine powder. This ion exchanger was used as a modifier for the carbon paste electrode which was prepared as described elsewhere [32]. The composition of the ion exchanger was confirmed by elemental analysis at the Micro-Analytical Center, Faculty of Science, Cairo university, to be 1:1 [Pm:TPB]. The calculated percentages of $\mathrm{C}, \mathrm{H}, \mathrm{N}$ and $\mathrm{S}$ were $81.4 \%$, $6.7 \%, 4.6 \%$ and $5.2 \%$ and the found ones were $80.5 \%$, $6.5 \%, 5.1 \%$ and $4.9 \%$, respectively.

\subsection{Construction of the Electrode [32]}

A Teflon holder (12 cm length) with a hole at one end (7 $\mathrm{mm}$ diameter, $3.5 \mathrm{~mm}$ depth) for the paste filling served as the electrode body. Electrical contact was made with a stainless steel rod through the center of the holder. This rod can move up and down by screw movement to press the paste down when renewal of the electrode surface is needed. The modified paste was prepared by mixing the weighed amount of Pm-TPB ion pair and high purity graphite with acetone. The mixture was homogenized, and the weighed amount of DOP was added to the mixture. Very intimate homogenization is then achieved by careful mixing with glass rod in agate mortar. The readyprepared paste was packed into the hole of the electrode body. The carbon paste was smoothed onto paper until it had a shiny appearance and the electrode was used di- rectly for potentiometric measurements without preconditioning requirements.

\subsection{Recommended Procedures}

\subsubsection{Construction of the Calibration Graphs}

Suitable increments of standard $\mathrm{Pm} . \mathrm{Cl}$ solution were added to $50 \mathrm{ml}$ of water to cover the concentration range from $1.0 \times 10^{6}$ to $1.0 \times 10^{2} \mathrm{M}$. For higher concentrations, separate solutions were used. In this solution, the sensor and the reference electrodes were immersed and the emf was recorded after 10 seconds, at $25^{\circ} \mathrm{C}$, after each addition, and plotted versus- $\log [\mathrm{Pm} . \mathrm{Cl}]$.

\subsubsection{Effect of $\mathrm{pH}$ on the Electrode Potential}

The effect of $\mathrm{pH}$ of the test solution on the potential values of the electrode system concentrations of $1.0 \times 10^{2}$ and $1 \times 10^{3} \mathrm{M}$ of Pm.Cl was studied. Aliquots of the drug solution $[50 \mathrm{ml}$ ] were transferred to $100 \mathrm{ml}$ cell and the tested electrode in conjunction with an $\mathrm{Ag} / \mathrm{AgCl} / 3 \mathrm{M}$ $\mathrm{KCl}$ reference electrode, and a combined glass electrode were immersed in this solution. The potential and $\mathrm{pH}$ readings were simultaneously recorded. The $\mathrm{pH}$ of the solution was varied over the range of $1.0-12.0$ by addition of small volumes of $0.1-1.0 \mathrm{M} \mathrm{HCl}$ and/or $\mathrm{NaOH}$ solutions. The $\mathrm{mV}$-readings were plotted against the $\mathrm{pH}$ of the above mentioned concentrations.

\subsubsection{Potentiometric Determination of Promethazine Hydrochloride}

The standard addition method was applied [33], in which small known increments of standard Pm.Cl solution 0.1 $\mathrm{M}$ was added to $50 \mathrm{ml}$ aliquot samples containing various amounts of pure $\mathrm{Pm} . \mathrm{Cl}$ or the pharmaceutical preparations. The change in potential reading was recorded for each increment and used to calculate the concentration of $\mathrm{Pm} . \mathrm{Cl}$ in the sample solution using the following equation:

$$
C_{X}=C_{S}\left(V_{S} / V_{X}+V_{S}\right)\left(10^{n(\Delta E / S)}-V_{X} / V_{X}+V_{S}\right)^{-1}
$$

where: $C_{X}$ and $V_{X}$ are the concentration and the volume of the unknown, respectively, $C_{S}$ and $V_{S}$ are the concentration and the volume of the standard, respectively, $S$ is the slope of the calibration graph, and $\Delta E$ is the change in milli volt due to addition of the standard.

For analysis of pharmaceutical preparations, appropriate volumes from syrup, containing 5.00, 10.00, 15.00, $20.00,25.00$ and $35.00 \mathrm{mg}$ of promethazine were taken as samples and completed to $50 \mathrm{ml}$ by doubly distilled water and the standard addition technique was applied as described above.

In potentiometric titration, aliquots containing 16.0 $96.0 \mathrm{mg}$ of $\mathrm{Pm} . \mathrm{Cl}$ were transferred into $100 \mathrm{ml}$ titration cell and diluted to $50 \mathrm{ml}$ with distillated water. The re- 
sulting solutions were titrated against $10^{-2} \mathrm{~mol} / \mathrm{L}$ NaTPB solution. The end points were determined from the conventional S-shaped curves and the first derivative method. The same procedure was applied for the pharmaceutical preparations.

\section{Results and Discussion}

\subsection{Composition and Characteristics of the Electrode}

In preliminary experiments carbon paste electrodes with and without ion-exchanger were prepared. The paste with no exchanger displayed no measurable response toward promethazine cations, whereas, in the presence of the proposed ion-exchanger Pm-TPB, the optimized sensor demonstrated appreciable response and remarkable selectivity for $\mathrm{Pm}^{+}$cations over several common organic and inorganic cations. We examined also the influence of the plasticizer type and concentration on the characteristics of the electrode using four plasticizers with different polarities including DBP, DINP, ONPOE and DOP (Figure 1). An electrode modified by $0.6 \%$ Pm-TPB and 6.2 $\%$ DOP as a plasticizer has a slope of $58 \mathrm{mV}$ per concentration decade (Table 1) and a linearity range of $1 \times 10^{-5}$ to $6 \times 10^{-2} \mathrm{M}$ of Pm.Cl. This composition was chosen for carrying out the subsequent studies and its electrochemical performance characteristics were systematically evaluated according to IUPAC recommendations [34].

\subsection{Electrode Response}

Response characteristics of the electrode under investigation are summarized in (Table 2). Detection limit was evaluated according to IUPAC recommendation [34].

\subsection{Effect of $\mathrm{pH}$ of the Test Solution}

Representative curves for the electrode are shown in

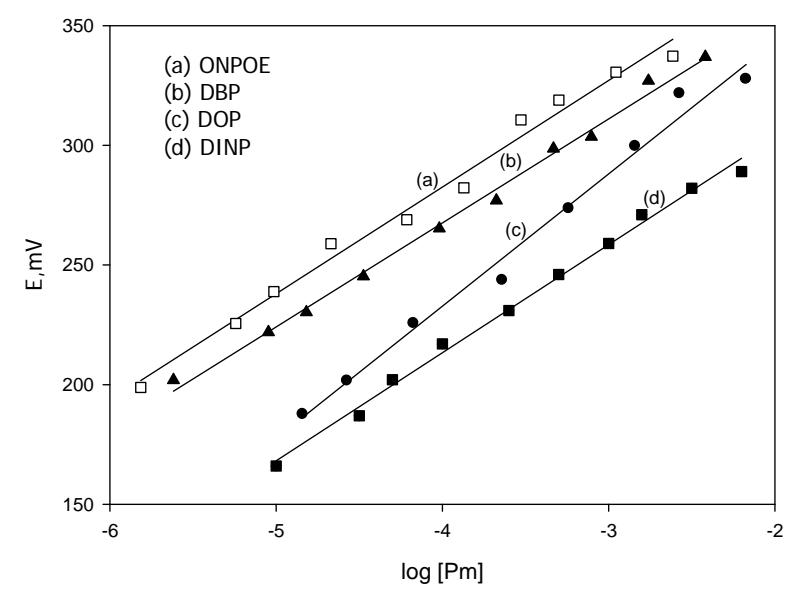

Figure 1. Effect of type and concentration of plasticizer on potential response of Pm-TPB MCPE.
Table 1. Composition of the Pm modified carbon paste electrode and the corresponding slopes of the calibration graphs at $25^{\circ} \mathrm{C} \pm 0.1^{\circ} \mathrm{C}$.

\begin{tabular}{|c|c|c|c|c|c|c|}
\hline \multicolumn{6}{|c|}{ Composition, \% w/w } & \multirow{2}{*}{$\begin{array}{c}\text { Slope } \\
\mathrm{mV} / \text { decade }\end{array}$} \\
\hline Graphite & Ion pair & DOP & DINP & ONPOE & DBP & \\
\hline $93.20^{*}$ & 0.6 & 6.2 & - & - & - & 58 \\
\hline 92.00 & 1.8 & 6.2 & - & - & - & 50 \\
\hline 90.70 & & 6.2 & - & - & - & 48 \\
\hline 93.20 & 0.6 & - & 6.2 & - & - & 39 \\
\hline 92.00 & 1.8 & - & 6.2 & - & - & 30 \\
\hline 90.70 & 3.1 & - & 6.2 & - & - & 22 \\
\hline 93.20 & 0.6 & - & - & - & 6.2 & 34 \\
\hline 92.00 & 1.8 & - & - & - & 6.2 & 20 \\
\hline 90.70 & 3.1 & - & - & - & 6.2 & 18 \\
\hline 93.20 & 0.6 & - & - & 6.2 & - & 30 \\
\hline 92.00 & 1.8 & - & - & 6.2 & - & 28 \\
\hline 90.70 & 3.1 & - & - & 6.2 & - & 26 \\
\hline
\end{tabular}

*Optimum composition.

Table 2. Response characteristics of the promethazine modified carbon paste electrode.

\begin{tabular}{lc} 
1) Usable concentration range (M) & $1 \times 10^{-5}-6 \times 10^{-2}$ \\
2) Lower detection limit (M) & $8 \times 10^{-6}$ \\
3) Working pH range & $4.2-6.8$ \\
4) Correlation coefficient & 0.9932 \\
5) Slope(mV/decade) & 58.00 \\
\hline
\end{tabular}

(Figure 2). The results indicate that at $\mathrm{pH}$ range of 4.2 6.8 , the potential of the electrode is independent of the value of $\mathrm{pH}$. At $\mathrm{pH}$ values lower than 4.2, the potential slightly increased, which can be related to penetration of hydronium ion, while the decreased potential that took place at $\mathrm{pH}$ values higher than 6.8 , is most probably attributed to the formation of the free promethazine base in the test solution.

\subsection{Selectivity of the Electrode}

The selectivity coefficients $K_{D, J^{2+}}^{\text {pot }}$ were evaluated by separate solution method SSM [35] for ions with charge numbers, applying the following equation:

$$
\log K_{D, J^{z+}}^{\text {pot }}=\left(E_{2}-E_{1}\right) / S+\log [D]-\log \left[J^{Z+}\right]^{1 / Z}
$$

where $E_{1}$ and $E_{2}$ are the electrode potentials in $10^{-2} \mathrm{M}$ $\mathrm{Pm} . \mathrm{Cl}$ and in $10^{-2} \mathrm{M}$ interferent $J^{+}$solutions, respectively and $S$ is the slope of the calibration graph.

The, $K_{D, J^{z+}}^{p o t}$ was also determined by the matched potential method MPM [36] for all types of ions and mole- 


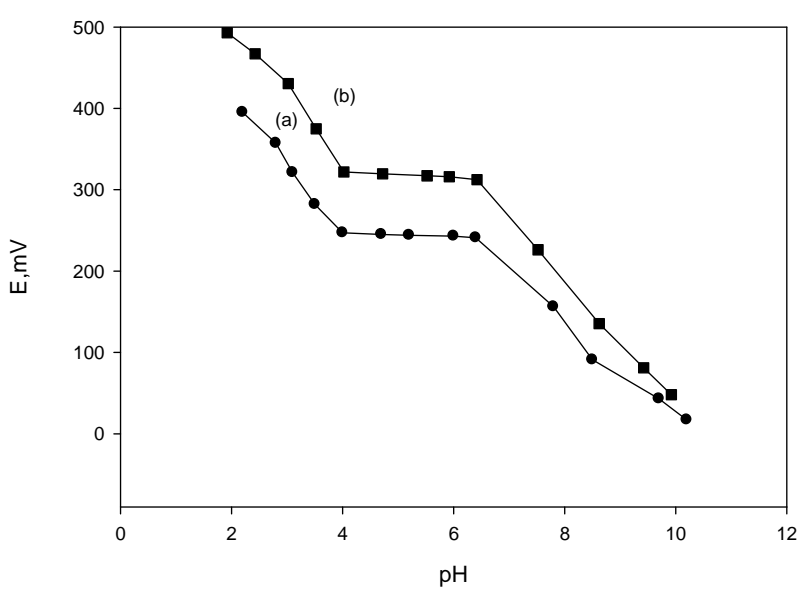

Figure 2. Effect of $\mathrm{pH}$ of test solution, $10^{-3} \mathrm{M}$ (a) and $10^{-2} \mathrm{M}$ (b) Pm.Cl on the potential response of Pm-TPB CMCPE.

cules. In this method, the potentiometric selectivity coefficient was defined as the activity ratio of primary and interfering ions that gives the same potential change under identical conditions.

At first, a known concentration $\left(C_{D^{*}}\right)$ of the primary ion is added to a reference solution that contains a fixed concentration $\left(C_{D}\right)$ of primary ions, and the corresponding potential difference $(\Delta E)$ was recorded and a solution of an interfering ion was added to the reference solution until the same potential change $(\Delta E)$ is recorded. The change in potential produced at the constant background of the primary ion must be the same in both:

$$
\log K_{D, J^{z+}}^{p o t}=\left(C_{D^{*}}-C_{D}\right) / C_{J}
$$

where, $C_{J}$ is the concentration of the interfering ion. The determined selectivity coefficients (Table 3) reflect a very high selectivity of the investigated electrode toward promethazine cations, with respect to many common inorganic cations, sugars and amino acids which are frequently present in biological fluids and pharmaceutical preparations. The inorganic cations did not interfere due to the differences in their motilities and permeabilities as compared to $\mathrm{Pm}^{+}$cations.

\section{Analytical Applications}

Promethazine was determined, in pure solutions and in pharmaceutical preparations, potentiometrically using the investigated electrode by both standard addition and potentiomertic titration methods. Representative titration curves are shown in (Figure 3). The mean recovery and the relative standard deviation values, for pure solution and pharmaceutical preparations, were calculated and summarized in (Table 4).

In pharmaceutical analysis, it is important to test the selectivity toward the excipients and fillers added to the pharmaceutical preparations. It is clear from the results
Table 3. Selectivity coefficients of Pm-TPB CMCP electrode.

\begin{tabular}{|c|c|c|}
\hline \multirow{2}{*}{ Inteferent ion } & \multicolumn{2}{|c|}{$K_{D, J^{2+}}^{\text {pot }}$} \\
\hline & MPM $^{*}$ & $\mathrm{SSM}^{* *}$ \\
\hline $\mathrm{Na}^{+}$ & $3.96 \times 10^{-4}$ & $3.36 \times 10^{-4}$ \\
\hline $\mathrm{K}^{+}$ & $6.00 \times 10^{-4}$ & $4.51 \times 10^{-4}$ \\
\hline $\mathrm{NH}_{4}^{+}$ & $2.62 \times 10^{-4}$ & $3.57 \times 10^{-4}$ \\
\hline $\mathrm{Li}^{+}$ & $4.52 \times 10^{-4}$ & $2.35 \times 10^{-4}$ \\
\hline $\mathrm{Hg}^{+2}$ & $2.81 \times 10^{-4}$ & $1.58 \times 10^{-4}$ \\
\hline $\mathrm{Ca}^{+2}$ & $3.66 \times 10^{-5}$ & $1.81 \times 10^{-5}$ \\
\hline $\mathrm{Sr}^{+2}$ & $4.27 \times 10^{-5}$ & $3.60 \times 10^{-5}$ \\
\hline $\mathrm{Mn}^{+2}$ & $5.75 \times 10^{-4}$ & $4.59 \times 10^{-4}$ \\
\hline $\mathrm{Ni}^{+2}$ & $7.14 \times 10^{-4}$ & $9.78 \times 10^{-4}$ \\
\hline $\mathrm{Ba}^{+2}$ & $2.93 \times 10^{-4}$ & $1.08 \times 10^{-4}$ \\
\hline $\mathrm{Cu}^{+2}$ & $2.54 \times 10^{-4}$ & $1.85 \times 10^{-4}$ \\
\hline $\mathrm{Pb}^{+2}$ & $3.00 \times 10^{-4}$ & $1.46 \times 10^{-4}$ \\
\hline $\mathrm{Cd}^{+2}$ & $7.67 \times 10^{-4}$ & $8.13 \times 10^{-4}$ \\
\hline $\mathrm{Mg}^{+2}$ & $4.83 \times 10^{-4}$ & $2.55 \times 10^{-4}$ \\
\hline $\mathrm{Zn}^{+2}$ & $2.69 \times 10^{-4}$ & $1.97 \times 10^{-4}$ \\
\hline $\mathrm{AL}^{+3}$ & $5.51 \times 10^{-4}$ & $2.58 \times 10^{-4}$ \\
\hline $\mathrm{Cr}^{+3}$ & $3.95 \times 10^{-4}$ & $1.75 \times 10^{-4}$ \\
\hline $\mathrm{Co}^{+2}$ & $6.72 \times 10^{-5}$ & $4.72 \times 10^{-5}$ \\
\hline Ascorbic acid & $6.63 \times 10^{-5}$ & - \\
\hline Glycine & $0.24 \times 10^{-5}$ & - \\
\hline Glucose & $4.01 \times 10^{-5}$ & - \\
\hline Cystine & $1.04 \times 10^{-5}$ & - \\
\hline Lysine & $1.32 \times 10^{-5}$ & - \\
\hline Alanine & $2.07 \times 10^{-5}$ & - \\
\hline Thiocol & $5.96 \times 10^{-5}$ & - \\
\hline
\end{tabular}

"SSM: Separate Solution Method; ** MPM: Matched Potential Method.

Table 4. Determination of promethazine in pure form and in pharmaceutical preparations by applying standard addition and potentio-metric titration methods.

\begin{tabular}{|c|c|c|c|}
\hline \multicolumn{4}{|c|}{ Standard addition method } \\
\hline Sample & Taken* & Recovery\% & $\mathrm{RSD}^{* *} \%$ \\
\hline Pure solution & $0.80-46.00$ & $99.7-100.3$ & $0.50-1.58$ \\
\hline $\begin{array}{l}\text { Phenergan } \\
\text { (antihistaminic) } 1 \mathrm{mg} / \mathrm{ml}\end{array}$ & $5.00-25.00$ & $98.7-99.5$ & $0.63-1.69$ \\
\hline $\begin{array}{c}\text { Phenergan } \\
\text { (expectorant) } 1 \mathrm{mg} / \mathrm{ml}\end{array}$ & $10.00-35.00$ & $97.3-99.3$ & $0.35-1.83$ \\
\hline \multicolumn{4}{|c|}{ Potentiometric titration } \\
\hline Pure solution & $16.00-96.00$ & $98.4-101.05$ & $0.56-1.83$ \\
\hline $\begin{array}{l}\text { Phenergan } \\
\text { (antihistaminic) } 1 \mathrm{mg} / \mathrm{ml}\end{array}$ & $16.00-80.00$ & $98.6-100.4$ & $0.80-1.52$ \\
\hline $\begin{array}{l}\text { Phenergan (expectorant) } \\
1 \mathrm{mg} / \mathrm{ml}\end{array}$ & $32.00-96.00$ & $97.4-100.08$ & $0.83-1.80$ \\
\hline
\end{tabular}

(mg per $50 \mathrm{ml}$ ); ${ }^{* *} \mathrm{RSD}$, relative standard deviation (four determinations). 
obtained for pharmaceutical preparations (Table 4) that these components and excipients do not interfere as indicated by high recovery and low standard deviation values. The results of the proposed electrode indicate high accuracy and precision of the present work (Table 5). These results were compared with those obtained from the official method (based on non aqueous titration of the drug with $0.1 \mathrm{~N}$ perchloric acid in the presence of anhydrous acetic acid and acetic anhydride and the end point was determined potentiometrically [37]) by applying of F-and t-tests [37]. The calculated F-values were found to be in the range $2.68-2.82$ which were lower than the tabulated value [9.12 at $95 \%$ confidence limit and 4 degrees of freedom] While, the t-values were found in the range $4.19-5.17$ which were lower than the tabulated value [5.84 at $99.9 \%$ confidence limit and 4 degrees of freedom]. This means that the present methods were of comparable precision to that of the official method and there was no significant difference between the mean values obtained by both methods. In order to establish whether the proposed methods exhibit any fixed or proportional bias, a simple linear regression of the taken milligrams against found was calculated [38] and the results of statistical treatments of the data were shown in (Table 5).

\section{Conclusion}

The proposed electrode based on Pm-TPB ion exchanger as the paste modifier offer a valuable technique for the determination of promethazine in pure solution and in pharmaceutical preparations. The inherent advantages of the proposed electrode were its rapid response, simple operation, and precise results, low cost, applicability over reasonable $\mathrm{pH}$ range with minimal sample pretreatment and direct application to the determination of promethazine in complex matrix without prior separation. The proposed methods of determination with the prescribed electrode were simple, sensitive, highly specific and had advantages over the previously described procedures for Pm.Cl determination since the interferences of the excipients and impurities were nullified.

Table 5. Statistical treatment of the data obtained for Promethazine using modified carbon paste electrode in comparison with the official method.

\begin{tabular}{cccccc}
\hline Method & $\mathrm{S}$ & $\mathrm{I}$ & $\mathrm{R}$ & $\begin{array}{c}\mathrm{F}-\mathrm{v} \text { alue } \\
(9.12)^{\mathrm{a}}\end{array}$ & $\begin{array}{c}\mathrm{t} \text {-value } \\
(5.84)^{\mathrm{b}}\end{array}$ \\
\hline $\begin{array}{c}\text { Standard } \\
\text { addition }\end{array}$ & 0.997 & 1.268 & 0.9999 & 2.8241 & 5.1754 \\
$\begin{array}{c}\text { Potentiometric } \\
\text { titration }\end{array}$ & 1.007 & -0.033 & 0.9996 & 2.6829 & 4.9166 \\
\hline
\end{tabular}

S: Slope of the regression line of $\mathrm{mg}$ taken versus $\mathrm{mg}$ found. I: intercept of the regression line. R: Correlation coefficient of the regression line. ${ }^{a} \mathrm{~F}-$ tabulated at $95 \%$ confidence limit. ${ }^{b}$ t-tabulated at $99.9 \%$ confidence limit.

\section{REFERENCES}

[1] P. Liu, S. Liang, B. J. Wang and R. C. Guo, "Development and Validation of a Sensitive LC-MS Method for the Determination of Promethazine Hydrochloride in Human Plasma and Urine," European Journal of Drug Metabolism and Pharmacokinetics, Vol. 34, No. 3-4, 2009, pp. 177-184.

[2] S. L. Yang, L. O. Wilkin and C. R. Clark, “Ahigh-Performanceliquid-Chromatographic Method for the Simultaneous Assay of Aspirin, Caffeine, Di-Hydro Codeine Tartarate and Promethazine Hydrochloride in a Capsule Formulation," Journal of Medical Economics, Vol. 11, No. 4, 1985, pp. 799-814.

[3] D. D. Borkar, V. P. Godse, Y. S. Bafana and A. V. Bhosale, "Simultaneous Estimation of Paracetamol and Promethazine Hydrochloride in Pharmaceutical Formulationsby a RP-HPLC Method," International Journal of ChemTech Research, Vol. 1, No. 3, 2009, pp. 667-670.

[4] B. J. Meakin, D. J. Davies, N. Cox and J. Stevens, "Chromatographic Determination of Promethazine Hydrochloride in Aqueous Solution," Analyst, Vol. 101, No. 1206, 2009, p. 720. doi:10.1039/an9760100720

[5] S. X. R. Spring, Y. H. L. Hong, S. X. R. Spring and Y. H. L. H. Ling, "High Performance Liquid Chromatography for Determination of Promethazine Hydrochloride Injection," Pharmaceutical Analysis Journal, Vol. 25, No. 9, 2005, pp. 139-141.

[6] S. Stavchanskya, J. Wallaceb, M. Chuea and J. Newburgera, "High Pressure Liquid Chromatographic Determination of Promethazine Hydrochloride in the Presence of Its Thermal and Photolytic Degradation Products," Journal of Liquid Chromatography, Vol. 6, No. 7, 1983, pp. 1333-1344. doi:10.1080/01483918308080002

[7] J. E. Wallace, J. E. Shimek, S. C. Harris and S. Stavchansky, "Determination of Promethazine in Serum by Liquid Chromatogphy," Clinical Chemistry Journal, Vol. 27, No. 2, 1981, pp. 253-255.

[8] S. Stavchanskya, J. E. Wallaceb, M. Chuea and P. Wua "Gas Liquid Chromatographic Determination of Promethazine Hydrochloride in Cocoa Butter-White Wax Suppositories," Indian Pharmaceutical Journal, Vol. 9, No. 6, 1983, pp. 989-998.

doi: $10.3109 / 03639048309042837$

[9] B. J. Meakin, D. J. G. Davies, N. Cox and J. Stevens, "Chromatographic Determination of Promethazine Hydrochloride in Aqueous Solution," Analyst, Vol. 101, No. 1206, 1976, pp. 720-727. doi:10.1039/an9760100720

[10] S. Stavchanskya, J. E. Wallaceb, M. Chuea and P. Wua, "Gas Liquid Chromatographic Determination of Promethazine Hydrochloride in Polyethylene Glycol Suppositories Using the Hall's Electrolytic Conductivity Detector," Analytical Letters Journal, Vol. 15, No. 16, 1982, pp. 1361-1372.

[11] J. M. Calatayud, S. N. Sarrion, A. S. Sampedro and C. G. Benito, "Determination of Promethazine Hydrochloride with Bromophenol Blue by a Turbidmetric Method and Flow Injection Analysis," Micro chemical Journal, Vol. 45, No. 2, 1992, pp. 129-136. 


\section{doi:10.1016/0026-265X(92)90004-M}

[12] J. L. Francisco, A. M. García, C. F. Alés, Barrero and J. M. B. Sendra. "Determination of Thiazinamium, Promazine and Promethazine in Pharmaceutical Formulations Using a CZE Method," Analytica Chimica Acta Journal, Vol. 535, No. 1-2, 2005, pp. 101-108.

[13] P. Kubacák, P. Mikus, I. Valásková and E. Havránek, "Determination of Promethazine Hydrochloride in Pharmaceuticals by Capillary Isotachophoresis," Methods and Findings in Experimental and Clinical Pharmacology, Vol. 27, No. 8, 2005, p. 529.

[14] N. N. Yong and B. Q. Zheng, "Differential Kinetic Spectrophotometric Determination of Chlorpromazine Hydrochloride and Promethazine Hydrochloride by Chemometric Method," Guang Pu Fenxi Chinese Journal, Vol. 22, No. 7, 2002, pp. 1364-1367.

[15] Q. Zhang, X. Zhan, C. Li, T. Lin, L. Li, X. Yin, N. He and Y. Shi, "Determination of Promethazine Hydrochloride and Its Preparations by Highly Accurate Nephelometric Titration," International Journal of Pharmaceutics, Vol. 302, No. 1-2, 2005, pp. 10-17.

[16] A. M. Idris, F. N. Assubaie and S. M. Sultan, "Ion-Pair Formation in Pharmaceutical Analysis Conduct Metric Determination of Promazine, Chlorpromazine, Promethazine, Imipramine and Ciprofloxacin Hydrochlorides in Pure Form, Drug Formulations and Urine," Micro Chimica Acta Journal, Vol. 134, No. 1-2, 2000, pp. 9-14.

[17] F. W. P. Ribeiro, A. S. Cardoso, R. R. Portela, J. E. S. Lima, S. A. S. Machado, P. L. Neto, D. D. Souza and A. N. Correia, "Electro analytical Determination of Promethazine Hydrochloride in Pharmaceutical Formulations on Highly Boron-Doped Diamond Electrodes," Electro Analysis Journal, Vol. 20, No. 18, 2008, pp. 2031-2039.

[18] X. Y. Hu and Z. Z. Leng, "Spectrophotometric Determination of Promethazine Hydrochloride," Yaохиe Xuebao, Vol. 27, No. 4, 1992, pp. 283-286.

[19] Y. Ni, L. Wanga and S. Kokot, "Voltammetric Determination of Chlorpromazine Hydrochloride and Promethazine Hydrochloride with the Use of Multivariate Calibration," Analytica Chimica Acta Journal, Vol. 439, No. 1, 2001, pp. 159-168.

[20] Z. S. Yang, J. Zhao, D. P. Zhang and Y. C. Liu, "Electrochemical Determination of Trace Promethazine Hydrochloride by a Pretreated Glassy Carbon Electrode Modified with DNA," Analytical Science Journal, Vol. 23, No. 5, 2007, pp. 569-572.

[21] X. Xi, L. Ming and J. Liu, "Voltammetric Determination of Promethazine Hydrochloride at a Multi-Wall Carbon Nanotube Modified Glassy Carbon Electrode," Drug Testing and Analysis Journal, Vol. 3, No. 3, 2011, pp. 182-186.

[22] P. Xiao, W. Wu, J. Yu and F. Zhao, "Voltammetric Sensing of Promethazine on Multi-Walled Carbon Nanotubes Coated Gold Electrode," International Journal of Electro Chemical Science, Vol. 2, No. 2, 2007, pp. 149-157.

[23] A. K. Hassan, B. Saad, S. A. Ghani, R. Adnan, A. A. Rahim, N. Ahmad, M. Mokhtar, S. T. Ameen and S. M. A. Araji, "Ionophore-Based Potentiometric Sensors for the Flow-Injection Determination of Promethazine Hy- drochloride in Pharmaceutical Formulations and Human Urine," Academic Journal, Vol. 11, No. 1, 2011, pp. 1028-1042.

[24] N. S. Nassory, S. A. Maki and B. A. Phalahy, "Preparation and Potentiometric Study of Promethazine Hydrochloride Selective Electrodes and Their Use in Determining Some Drugs," Journal of Chemistry, Vol. 32, No. 2, 2008, pp. 539-548.

[25] H. S. Gowda and K. A. Padmaji, "Spectrophotometric Studies on Platinum Promethazine Hydrochloride Complex," Micro Chemical Journal, Vol. 25, No. 3, 1980, pp. 396-402. doi:10.1016/0026-265X(80)90281-7

[26] D. Daniel and I. G. R. Gutz, "Flow Injection Spectro Electro Analytical Method for the Determination of Promethazine Hydrochloride in Pharmaceutical Preparations," Analytical Chimica Acta, Vol. 494, No. 1-2, 2003, pp. 215-224.

[27] M. B. Devani, B. N. Suhagia and S. A. Shah, "Spectrophotometric Determination of Promethazine Hydrochloride in Bulk Powder and In Its Dosage Forms," Indian Journal of Pharmaceutical, Vol. 61, No. 2, 1999, pp. $110-112$

[28] M. J. Saif and J. Anwar, "New Spectrophotometer Method for the Determination of Promethazine- $\mathrm{HCl}$ from Pure and Pharmaceutical Preparations," Talanta Journal, Vol. 31, No. 5, 2005, pp. 869-872.

[29] K. C. Ramesh, B. G. Gowda and J. Keshavayya, "Spectrophotometric Determination of Promethazine Hydrochloride in Pharmaceutical Formulations," Indian journal Pharmaceutical Science, Vol. 65, No. 4, 2003, pp. 432 435.

[30] M. Q. A. Abachi, T. S. A. Ghabsha and E. S. Salih, “Application of Promethazine Hydrochloride as a Chromogenic Reagent for the Spectrophotometric Determination of Aniline and Its Substituent's," Micro Chemical Journal, Vol. 41, No. 1, 1990, pp. 64-71. doi:10.1016/0026-265X(90)90096-N

[31] S. M. Sultan, Y. A. M. Hassan and A. M. Abulkibash, "Chemiluminescence Assay of Promethazine Hydrochloride Using Acidic Permanganate Employing Flow Injection Mode Operated with Syringe and Peristaltic Pumps," Talanta Journal, Vol. 59, No. 6, 2003, pp. 1073-1080.

[32] H. Ibrahim, Y. M. Issa and H. M. A. Shawish, "Chemically Modified Carbon Paste Electrode for the Potentiometric Determination of Dicylomine Hydrochloride in Batch and in FIA Conditions," Analytical Sciences, Vol. 20, No. 6, 2004, pp. 911-916. doi:10.2116/analsci.20.911

[33] S. E. A. Karim, R. M. E. Nashar and A. H. Abadi, "Potentiometric Determination of Imatinib under Batch and Flow Injection Analysis Conditions," International Journal of Electro Chemistry Science, Vol. 7, No. 10, 2012, pp. 9668-9681.

[34] R. P. Buck and E. Lindner, "Recommendations for Nomenclature of Ion Selective Electrodes. IUPAC Recommendations," Pure and Applied Chemistry, Vol. 66, No. 12, 1994, pp. 227-236.

[35] G. G. Guilbault, R. A. Drust, M. S. Frant, H. Freiser, E. H. Hansehen, T. S. Light, E. Pungor, G. A. Rechnitz, N. M. Rice, T. J. Rohm, W. Simon and J. D. R. Thomas, "Pico- 
liter Cell Volume Potentiometric Detector for Open-Tubular Column LC," Pure and Applied Chemistry, Vol. 48, No. 29, 1976, pp. 127-132.

[36] Y. Umezawa, P. Buhlmann, K. Umezawa, K. Tohda and S. Amemiya, "Potentiometric Selectivity Coefficient of Ion Selective Electrodes, Part one, Inorganic Cations," Pure and Applied Chemistry, Vol. 72, No. 10, 2000, pp.
1851-2082.

[37] J. C. Miller and J. N. Miller, "Statistics in Analytical Chemistry," Ellis Horwood Chichester, England, 1988.

[38] British Pharmacopeia, "Medicinal and Pharmaceutical Substances," Vol. 1, Stationary Office Ltd., Cambridge, 2002. 